\title{
Heat tolerance of titanium boride and titanium nitride contacts to gallium arsenide
}

\author{
Ye. F. Venger, V. V. Milenin, I. B. Ermolovich, R. V. Konakova, D. I. Voitsikhovskiy, *I. Hotovy, \\ $* * V$. N. Ivanov \\ Institute of Semiconductor Physics, National Academy of Sciences of Ukraine, Kyiv, 252028, Ukraine, \\ phone: (38044) 26561 82; fax: (38044) 26583 42; e-mail: konakova@eee.semicond.kiev.ua \\ *Slovak University of Technology, 81219 Bratislava, Slovakia \\ **State Scientific-Research Institute “Orion”, Kyiv, 252057, Ukraine
}

\begin{abstract}
For contacts prepared from titanium borides by and nitrides ion-plasma sputtering onto gallium arsenide both formation mechanisms and thermal stability were investigated. We used a combination of structural, secondary-emission, optical and electrophysical methods, such as electronography, $X$-ray diffraction, atomic force microscopy, Auger electron spectroscopy, secondary-ion mass spectrometry, taking photoluminescence spectra and $I-V$ curves. A physical model for contact formation was proposed. According to it, $\mathrm{B}_{x} \mathrm{Ga}_{1-x} \mathrm{As}\left(\mathrm{GaN}_{\mathrm{r}} \mathrm{As}_{1-\mathrm{x}}\right)$ solid solutions are formed at the phase interfaces when titanium borides (nitrides) are deposited. The defects are produced in the semiconductor near-surface regions during heterostructure formation and further heat treatment. The correlation between the physico-chemical interactions at contact interfaces and the contact electrophysical parameters occurs through these defects. The objects of our investigation demonstrated high thermal stability. This was due to their two-layer structure formed by components having well-pronounced antidiffusion properties. As a result, the interdiffusion processes at the phase interfaces are drastically weakened.
\end{abstract}

Keywords: metal - semiconductor contacts, titanium borides, titanium nitrides, thermal stability.

Paper received 12.11.99; revised manuscript received 15.04.99; accepted for publication 19.04.99.

\section{Introduction}

Up to date it has been ascertained that degradation of the metal - semiconductor structures operating under extreme conditions (high temperatures, high-power electromagnetic fields, exposition to various radiations, etc.) is determined by both mass transport features and mechanisms of solid-state reactions between the contacting pairs. The influences actions lead to changes in a structural-phase state of interfaces, the degree of their uniformity, the impurity-defect composition of the semiconductor near-contact area, etc. All the above factors cause, in the long run, modification (degradation) of the contact electrophysical parameters. To obtain metal $-\mathrm{A}^{3} \mathrm{~B}^{5}$ structures that are tolerant to external influences one has to choose such metal alloys and compositions that could essentially reduce the diffusion interaction between the metal and semiconductor layers. The titanium borides and nitrides seem to be promising in this respect. This paper deals with investigation of several $\operatorname{TiB}_{x}\left(\mathrm{TiN}_{x}\right)$ GaAs structures.

\section{Experimental procedure}

We used GaAs:Te epitaxially grown structures to prepare samples for studies. The $n$-layer was 1.6 to $2.5 \mu \mathrm{m}$ thick. The charge carrier concentration in the active layer was $(0.7-1.1) \cdot 10^{16} \mathrm{~cm}^{-3}$. After photon cleaning of the above epitaxial films, the $\mathrm{TiB}_{x}$ and $\mathrm{TiN}_{x}$ films were deposited onto them using magnetron sputtering of the pressed powder targets in the argon atmosphere or in the mixture of argon with nitrogen (for $\mathrm{TiB}_{x}$ films) or thermionic reactive synthesis (for $\mathrm{TiN}_{x}$ films); the substrate temperature was $\mathrm{T}_{\text {sub }}=200{ }^{\circ} \mathrm{C}$. Thicknesses of metal films did not exceed $0.1 \mu \mathrm{m}$, as a rule. The contacts obtained were annealed for $1 \mathrm{~min}$. in a hydrogen flow at temperatures up to $800{ }^{\circ} \mathrm{C}$.

To study the mechanisms of contact structures formation and their thermal stability, we have used a complex of methods including structural (electronography, $\mathrm{X}$-ray diffraction (XRD)), optical (photoluminescence) and electrophysical ( $I-V$ curves) ones. The atomic composition of the prepared samples was studied using the 


\section{Ye. F. Venger et al.: Heat tolerance of titanium boride and titanium ...}

Auger electron spectroscopy (AES) combined with layer-by-layer ion etching ( $\mathrm{Ar}^{+}$ions of energy $3 \mathrm{keV}$ ), as well as the secondary ion mass spectrometry (SIMS). The atomic force microscopy (AFM) was also used.

\section{Results and discussion}

The electron diffraction patterns taken for the deposited films (100 nm thick) of titanium borides and nitrides indicated that the films were quasiamorphous. These results were confirmed by XRD measurements performed for thicker films. To illustrate, for $\mathrm{TiN}_{x}$ films (about $1 \mathrm{~mm}$ thick) the fractions of amorphous and polycrystalline phases were 70 and $30 \%$, respectively, and varied with increase of the deposited film thickness. Heat annealing of these films changes the above fractions (that of the crystalline phase grows) and also leads to formation of bigger grains with a more perfect structure. For the quasiamorphous fine-grained $(\approx 0.03 \mu \mathrm{m})$ layers $1 \mathrm{~mm}$ thick the recrystallization under heat annealing occurred more actively.

Modification of the deposited layers structure due to annealing was accompanied by changes in the film plane stresses: the macrocompressions changed for macroexpansions. Such changes were sometimes rather large. This is qualitatively confirmed, for example, by the morphology of $\mathrm{Au}$ - Mo - $\mathrm{TiB}_{x}$ - GaAs structures (annealed at 600 and $800{ }^{\circ} \mathrm{C}$ ) obtained with AFM (Fig. 1). One can see that the appeared thermal stresses caused cracking of deposited $\mathrm{TiB}_{x}$ films.

The data on Auger profiling (Figs. 2, 3) for the deposited titanium boride (nitride) films testify that, along with the principal components, they contain rather big quantities of oxygen and carbon. The Ti affinity to oxygen is high, so the oxygen presence in the reaction zone at the stage of film formation causes the oxide phases production. The presence of chemically inert carbon hinders full completion of structural modifications in the deposited layers. Annealing of such films stimulates their further structural-chemical modification during which the $\mathrm{Ti}-\mathrm{O}-\mathrm{B}(\mathrm{N})$ phases of variable composition play a dominant role. The structural-phase modification of the deposited layers due to heat annealing up to $600{ }^{\circ} \mathrm{C}$ does not lead to substantial smearing of the interphase boundaries. When the annealing temperature is increased up to $800{ }^{\circ} \mathrm{C}$, then the barrier properties of deposited films abruptly degrade, and substantial heteropair components intermixing is observed. This intermixing is more pronounced in the $\mathrm{TiB}_{x}$-based structures (Fig. 3). The structural-phase modification of condensed layers causes the transformation of the impurity-defect composition of the semiconductor near-contact regions.

Shown in Figs. 4, 5 are the photoluminescence (PL) spectra, measured at $77 \mathrm{~K}$ for the near-contact regions of $\mathrm{TiB}_{x}-\mathrm{GaAs}$ and $\mathrm{TiN}_{x}-\mathrm{GaAs}$ structures, respectively. One can find five bands in the PL spectra of both structures, with $h v_{\max }=1.54 ; 1.33 ; 1.20 ; 1.01$ and $0.765 \mathrm{eV}$. The dependencies of their intensities on the annealing temperature are shown in Figs. 6, 7. The principal features of the PL properties of these structures are as follows:

1) The PL spectra involve a great number of superimposing broad bands. This fact indicates the presence of a considerable number of structural defects in the GaAs near-contact regions.

2) For the initial structures, the $1.01 \mathrm{eV}$ band is the most intensive one. This band is related to the radiative capture of a free electron by a $\mathrm{Cu}_{\mathrm{Ga}}$ individual acceptor center (see [1]). Copper, apparently, serves as an uncontrollable impurity in the structures studied. Another PL band observed by us, with $h v_{\max }=1.33 \mathrm{eV}$, seems also to be related to the copper impurities. The centers responsible for it are the $\left(\mathrm{Cu}_{\mathrm{Ga}}+\mathrm{D}\right)$ complexes; here, $\mathrm{D}$ is a donor, either intrinsic $\left(\mathrm{V}_{\mathrm{As}}\right)$ or impurity one (Te, Sn, Si) [2]. In the initial state, such a donor is, more probably, a Te atom, since the initial epitaxial layers were doped with Te.

3) Heat annealing at $400{ }^{\circ} \mathrm{C}$ leads to some redistribution of the PL bands intensities, as well as to their growth. The latter is more pronounced in the $\mathrm{TiB}_{x}-\mathrm{GaAs}$ structures. This fact is an evidence that the $\mathrm{TiN}_{x}$-GaAs structures are more heat-tolerant (as concerning the defect states transformation) than the $\mathrm{TiB}_{x}$-GaAs structures. On the other hand, the PL intensity growth in the $\mathrm{TiB}_{x}$ GaAs structures over the whole spectral range seems to be due to improving structural perfection of the nearcontact region accompanied by weakening of the nonradiative recombination channel.

After heat annealing at $400{ }^{\circ} \mathrm{C}$ for both types of contacts the $1.20 \mathrm{eV}$ band intensity in the near-contact regions grows more than that of other impurity-defect bands. (For the $1.20 \mathrm{eV}$ band, the $\left(\mathrm{V}_{\mathrm{Ga}}+\mathrm{D}\right)$ complexes serve as the luminescence centers [3].) This may stem from the enrichment of the near-contact region with gallium vacancies, which occurs due to Ga diffusion from the near-contact region (and, probably, from the semiconductor bulk) to the metallization layer, as a result of the interphase interactions between metallization layers and the semiconductor. Taking into account the similarity of $\mathrm{B}$ and $\mathrm{Ga}$ outer electron shells, one can also suppose that, with an excess of $\mathrm{Ga}$ vacancies, the $\mathrm{B}_{x} \mathrm{Ga}_{1-x}$ As solid solution can be formed at early stages of the boride film growth (see below).

In the $\mathrm{TiB}_{x}-\mathrm{GaAs}$ structures the intensities of all the impurity-defect bands decrease at $600{ }^{\circ} \mathrm{C}$. The only exception is the $1.33 \mathrm{eV}$ band whose intensity grows slightly. This seems to be due to formation of the $\left(\mathrm{Cu}_{\mathrm{Ga}}+\mathrm{V}_{\mathrm{as}}\right)$ complexes. Such a conclusion is based on the fact that at these temperatures the As atoms begin to interact intensively with $\mathrm{Ti}$ atoms from the metallization layer. As a result, the $\mathrm{Ti}$ - As compound is formed [4], and the semiconductor is enriched with $\mathrm{V}_{\mathrm{As}}$. The drop in the $1.01 \mathrm{eV}$ band intensity is stipulated by the fact that some portion of its luminescence centers takes part in the above complexes formation. Such an opposite behavior of the 1.01 and $1.33 \mathrm{eV}$ bands intensities under annealing is observed for the $\mathrm{TiN}_{x}-$ GaAs structures, too. 


\section{Ye. F. Venger et al.: Heat tolerance of titanium boride and titanium ...}
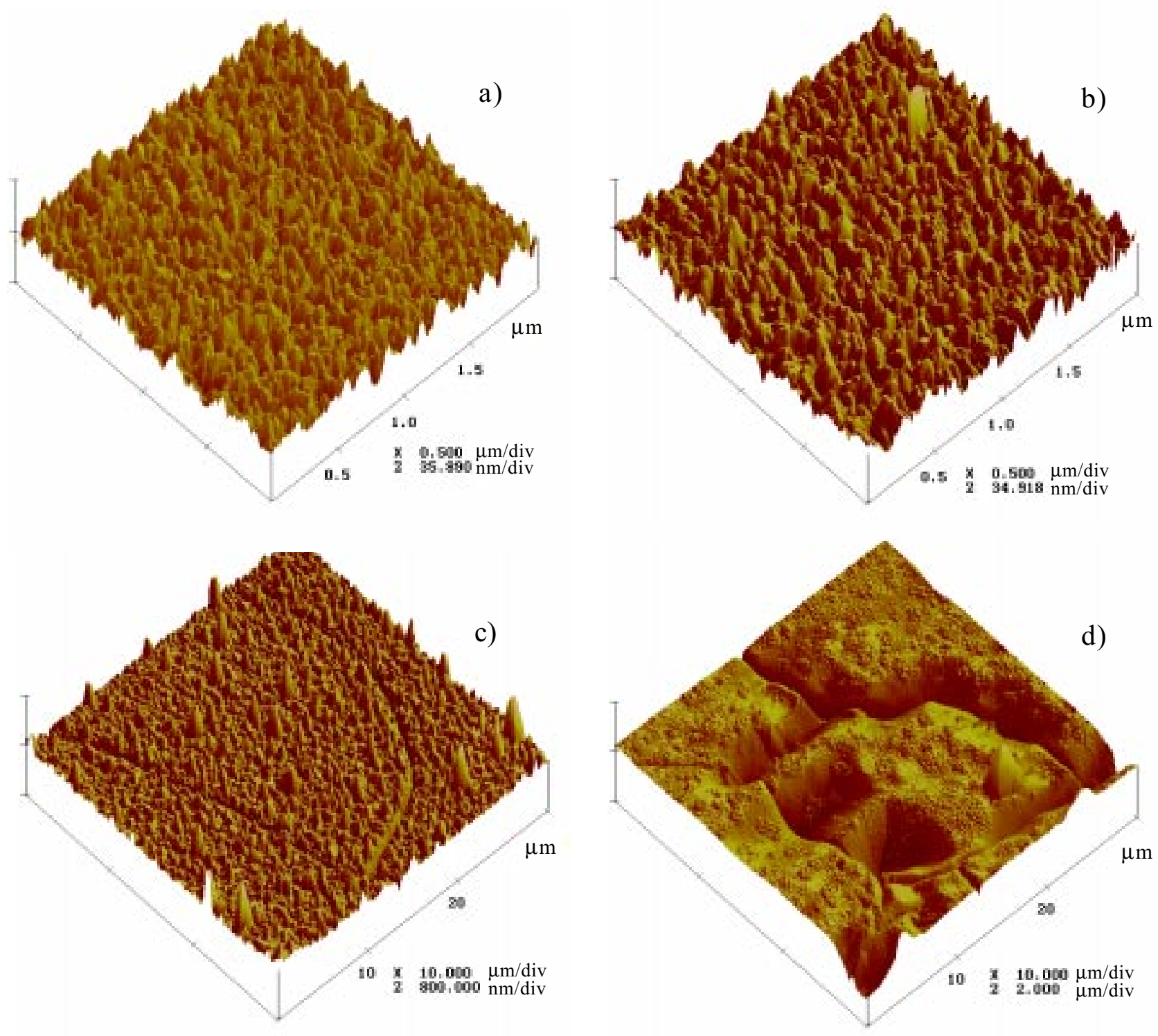

Fig. 1. Morphology changes for the $\mathrm{Au}-\mathrm{Mo}-\mathrm{TiB}_{\mathrm{x}}-\mathrm{GaAs}$ contact under different annealing conditions: $\mathrm{a}$ - initial sample; b, c, $\mathrm{d}$ - after annealing at 400,600 and $800{ }^{\circ} \mathrm{C}$, respectively.

It should be also noted that in both structures the 1.01 and $0.765 \mathrm{eV}$ bands behave similarly. This indicates that they are related to each other. We assume that the $0.765 \mathrm{eV}$ band stems from the intracenter radiative transitions in the $\left(\mathrm{Cu}_{\mathrm{Ga}}{ }^{2+}\right)^{-}$ions (that are responsible for the $1.01 \mathrm{eV}$ band). Their unoccupied $3 \mathrm{~d}^{9}$ shell is splitted in the crystal as a result of the spin-orbital interaction, similarly to the case of the $\mathrm{Cu}_{\mathrm{Cd}}{ }^{2+}$ ion in $\mathrm{CdS}: \mathrm{Cu}$ [5].

Heat annealing at $800{ }^{\circ} \mathrm{C}$ leads to dissociation of complex centers responsible for the 1.20 and $1.33 \mathrm{eV}$ bands. As a result, their intensities decrease (while that of the $1.01 \mathrm{eV}$ band grows) and become practically the same as in the initial state.
4) The principal distinction of the PL spectra in the near-contact regions of the structures studied consists in the presence of the free exciton radiation bands with peaks at $1.54 \mathrm{eV}$ (for the $\mathrm{TiB}_{x}-\mathrm{GaAs}$ structure) and $1.57 \mathrm{eV}$ (for the $\mathrm{TiN}_{x}-\mathrm{GaAs}$ structure), while the $\mathrm{TiN}_{x}$ - GaAs gap at $77 \mathrm{~K}$ is $1.50 \mathrm{eV}$ [6]. This fact seems to be a direct evidence that thin layers of solid solutions $\left(\mathrm{B} \mathrm{Ga}_{1-x} \mathrm{As}\right.$ and $\mathrm{GaN}_{x} \mathrm{As}_{1-x}$, respectively) are formed at the interfaces of the structures studied. These solid solutions are of high structural perfection. The abrupt quenching of the exciton band, as well as other bands, after heat annealing at $800{ }^{\circ} \mathrm{C}$ serves as an evidence that a great number of additional nonradiative recombination centers have ap- 
Ye. F. Venger et al.: Heat tolerance of titanium boride and titanium ...
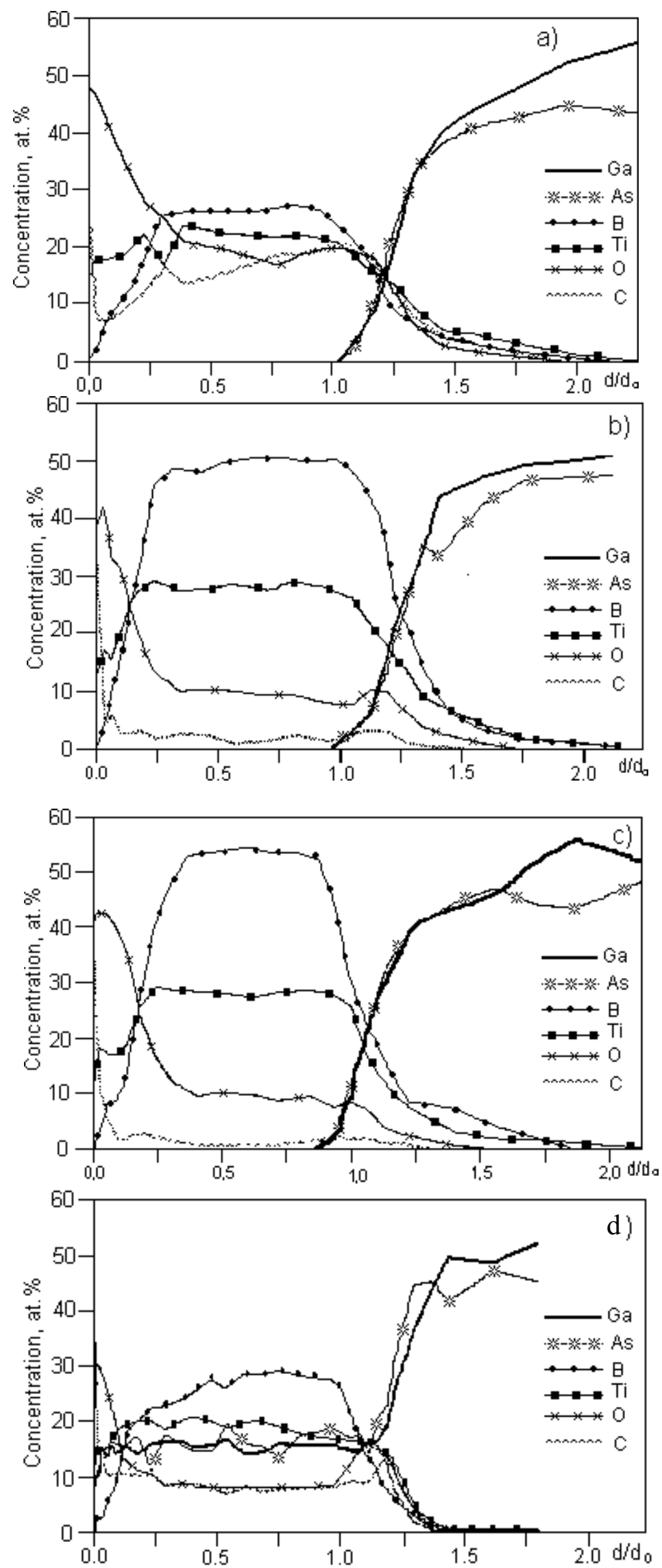

Fig. 2. Auger concentration depth profiles for the $\mathrm{TiB}_{x}-\mathrm{GaAs}$ contact components taken before (a) and after heat annealing at 400 (b), 600 (c) and $800^{\circ} \mathrm{C}(\mathrm{d})$. 
Ye. F. Venger et al.: Heat tolerance of titanium boride and titanium ...
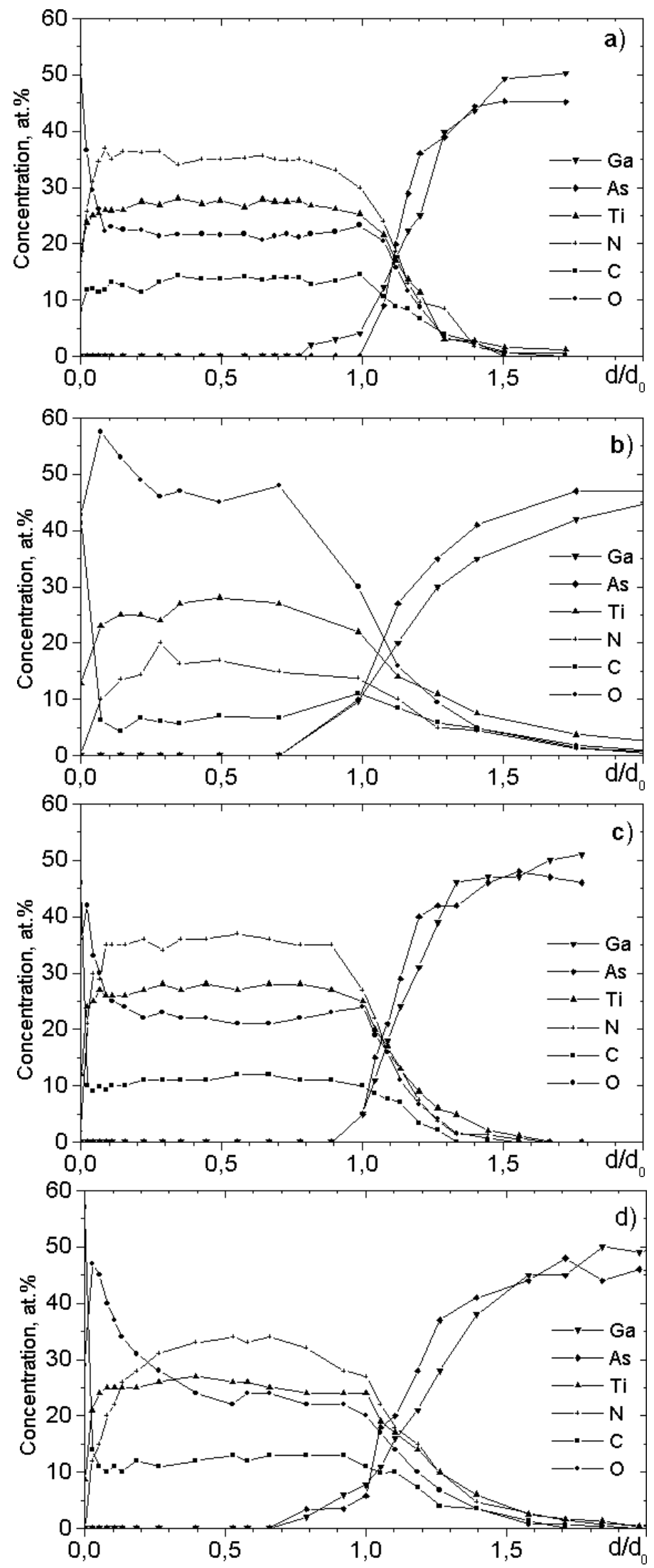

Fig. 3. Auger concentration depth profiles for the $\mathrm{TiN}_{x}-\mathrm{GaAs}$ contact components taken before (a) and after heat annealing at 400 (b), 600 (c) and $800{ }^{\circ} \mathrm{C}(\mathrm{d})$. 
Ye. F. Venger et al.: Heat tolerance of titanium boride and titanium ...

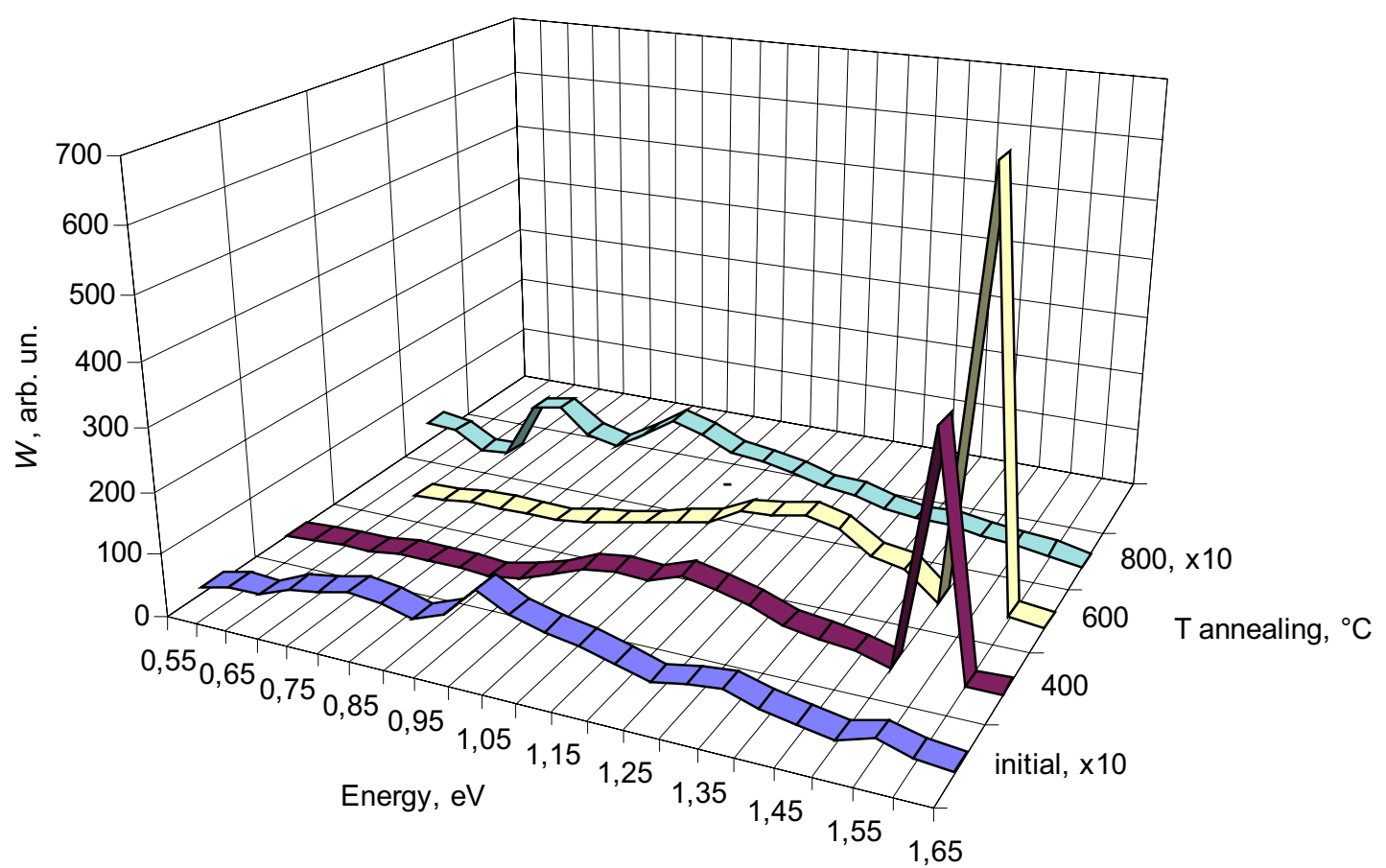

Fig. 4. Photoluminescence spectra taken at $\mathrm{T}=77 \mathrm{~K}$ for the near-contact layers of the $\mathrm{TiB}_{x}$ - GaAs structures.

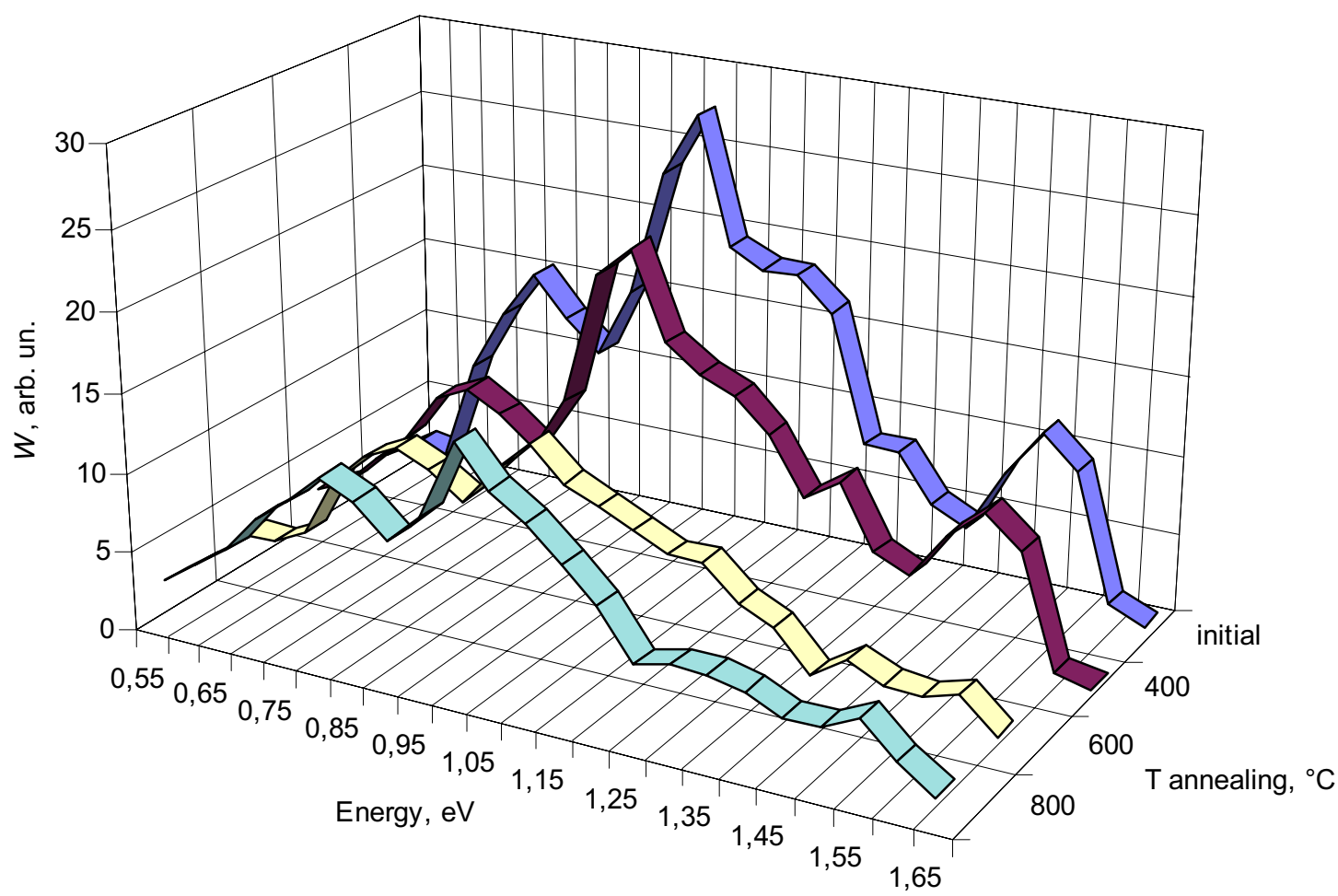

Fig. 5. Photoluminescence spectra taken at $\mathrm{T}=77 \mathrm{~K}$ for the near-contact layers of the $\mathrm{TiN}_{x}-\mathrm{GaAs}_{\text {structures. }}$ 


\section{Ye. F. Venger et al.: Heat tolerance of titanium boride and titanium ...}

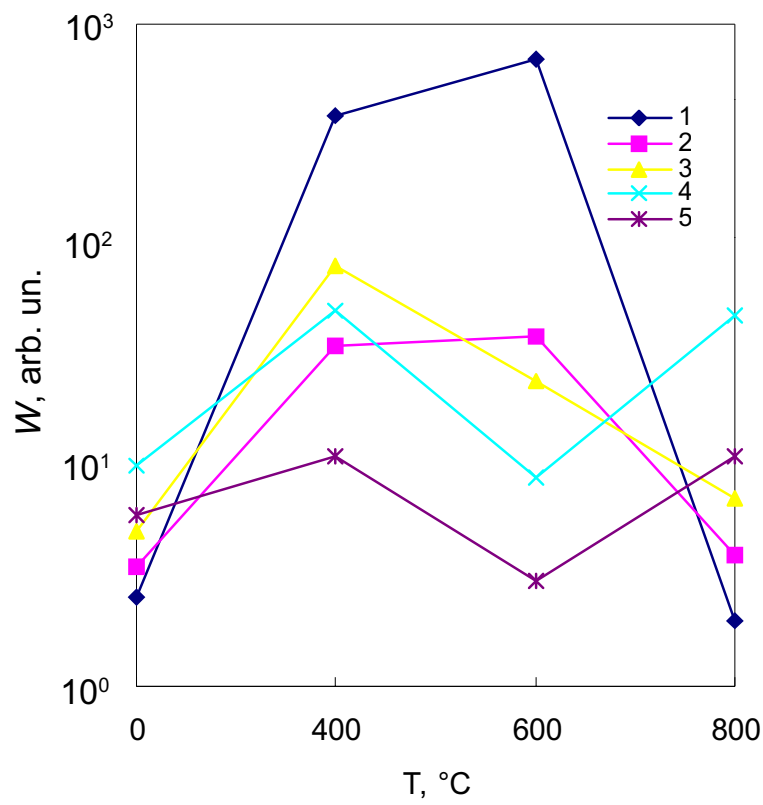

Fig. 6. The intensities of the photoluminescence bands vs annealing temperature curves for the $\mathrm{TiB}_{x}-\mathrm{GaAs}$ structures: $h v_{\max }=1.54$ (1), 1.33 (2), 1.20 (3), 1.01 (4) and $0.765 \mathrm{eV}$ (5).

peared, by this moment.

The formation of solid solutions at the interfaces of the structures studied, as well as possible presence of copper there, were confirmed by the results of SIMS measurements performed for the contact regions (see Table 1). Peaks from ions of masses 84, 159 and 155, as well as from clusters (apparently, GaAsTi) of atomic mass 192 (formed by $\mathrm{Ti}$ atoms that are not bound to nitrogen) presented in spectra can provide an evidence for the above conclusion.

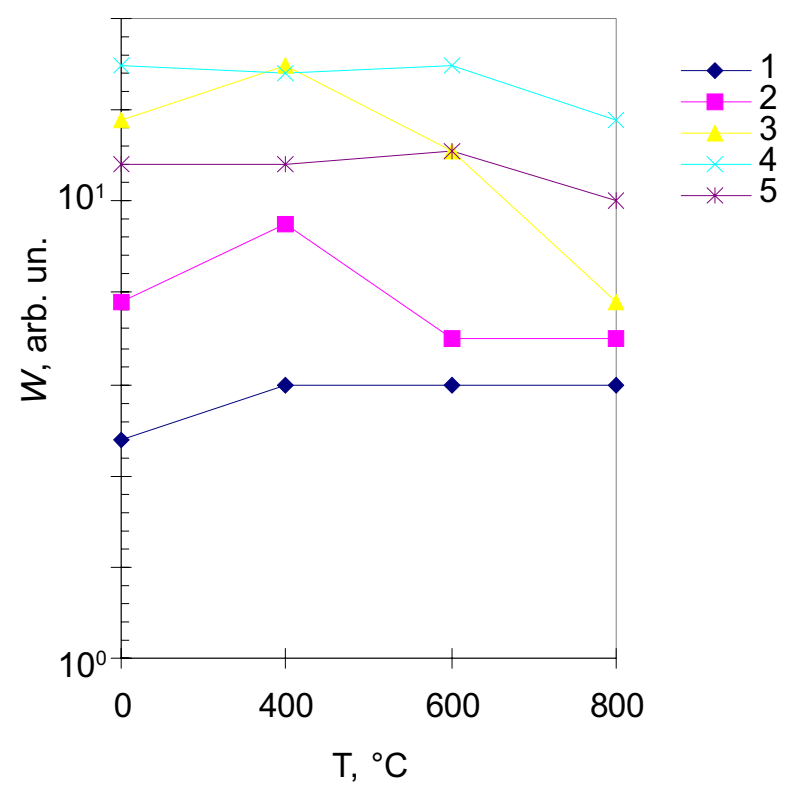

Fig. 7. The intensities of the photoluminescence bands vs annealing temperature curves for the $\mathrm{TiN}_{x}$ - GaAs structures: $h v_{\max }=1.54(1), 1.33(2), 1.20(3), 1.01$ (4) and $0.765 \mathrm{eV}(5)$.

A more uncertain situation appears when one tries to identify the $\mathrm{Cu}$ impurity whose spectra overlap those of $\mathrm{TiO}$. It seems that there exists a superposition of signals from $\mathrm{TiO}$ and $\mathrm{Cu}$ in the measured spectra. Indeed, small intensity variations in the spectral lines, which are observed after heat annealing, as well as the fact that the ratio of their intensities differs from that for the case of natural content of $\mathrm{Cu}$ isotopes, allow to confirm that uncontrolled $\mathrm{Cu}$ impurities are present in the samples studied.

Table 1. The results of mass-spectrometry studies for $\mathrm{TiN}_{x}-\mathrm{GaAs}$ and $\mathrm{TiB}_{x}-\mathrm{GaAs}$ heterostructures.

\begin{tabular}{|c|c|c|c|c|c|c|}
\hline \multirow{3}{*}{ Heterostructure } & \multirow{3}{*}{ Compound } & \multirow{3}{*}{ Mass, arb.un. } & \multicolumn{4}{|c|}{ Ion current in the transition layer, arb. un. } \\
\hline & & & Initial state & After her & ling at a & ature of: \\
\hline & & & & $400{ }^{\circ} \mathrm{C}$ & $600{ }^{\circ} \mathrm{C}$ & $800{ }^{\circ} \mathrm{C}$ \\
\hline \multirow{5}{*}{$\operatorname{TiN}_{x}-\mathrm{GaAs}$} & TiN & 62 & $10^{4}$ & $10^{4}$ & $10^{4}$ & $1.2 .10^{4}$ \\
\hline & $\mathrm{GaN}$ & 84 & 40 & 40 & 30 & 50 \\
\hline & GaAsN & 159 & 10 & 8 & 5 & 7 \\
\hline & GaAsTi & 192 & 50 & 30 & 10 & - \\
\hline & $\mathrm{Cu}(\mathrm{TiO})$ & 64 & $5.10^{4}$ & $8.10^{4}$ & $6.10^{4}$ & $1.2 .10^{4}$ \\
\hline \multirow{5}{*}{$\mathrm{TiB}_{x}-\mathrm{GaAs}$} & TiB & 54 & $4.10^{4}$ & $10^{5}$ & $7.10^{4}$ & $2.10^{4}$ \\
\hline & BAs & 86 & - & - & - & - \\
\hline & GaBAs & 155 & 50 & 80 & 80 & 90 \\
\hline & GaAsTi & 192 & $3.10^{2}$ & $3.10^{2}$ & $3.10^{2}$ & $8.10^{2}$ \\
\hline & $\mathrm{Cu}(\mathrm{TiO})$ & 64 & $4.10^{5}$ & $4.10^{5}$ & $6.10^{5}$ & $4.10^{5}$ \\
\hline
\end{tabular}




\section{Ye. F. Venger et al.: Heat tolerance of titanium boride and titanium ...}

The set of the results obtained indicates that the electrophysical parameters of the diode structures formed using $\mathrm{TiB}_{x}$ - and $\mathrm{TiN}_{x}$-based antidiffusion barriers will remain rather stable under thermal treatments. This conclusion has been checked by measurements of the $I-V$ curves for the $\mathrm{Au}$ - TiB - GaAs contact structures.

Shown in the Fig. 8 are the diode $I-V$ curves taken before and after heat annealing. For the initial structures, the forward branches of $I-V$ curves are nonlinear in the $\ln I_{F}-V$ coordinates. At small biases there is a part corresponding to excess current, while for big biases the current practically does not depend on voltage. The reverse branch of the $I-V$ curve is a power function of the bias voltage. Heat annealing causes changes in the forward branches of the $I-V$ curves, while the reverse branches remain the power functions of the bias voltage, and only a value of the reverse current is changed. Taking into account the results of PL studies, one may assume that the common reason for the $I-V$ curve deviation from that characteristic of the ordinary thermionic mechanism of current flow (that usually takes place in diodes based on GaAs with a definite doping level [7]) lies in the modification of concentration and a type of defects responsible for deep local levels in the GaAs gap. As known (and shown also in this paper using PL studies), when a metal film is deposited onto a semiconductor surface,
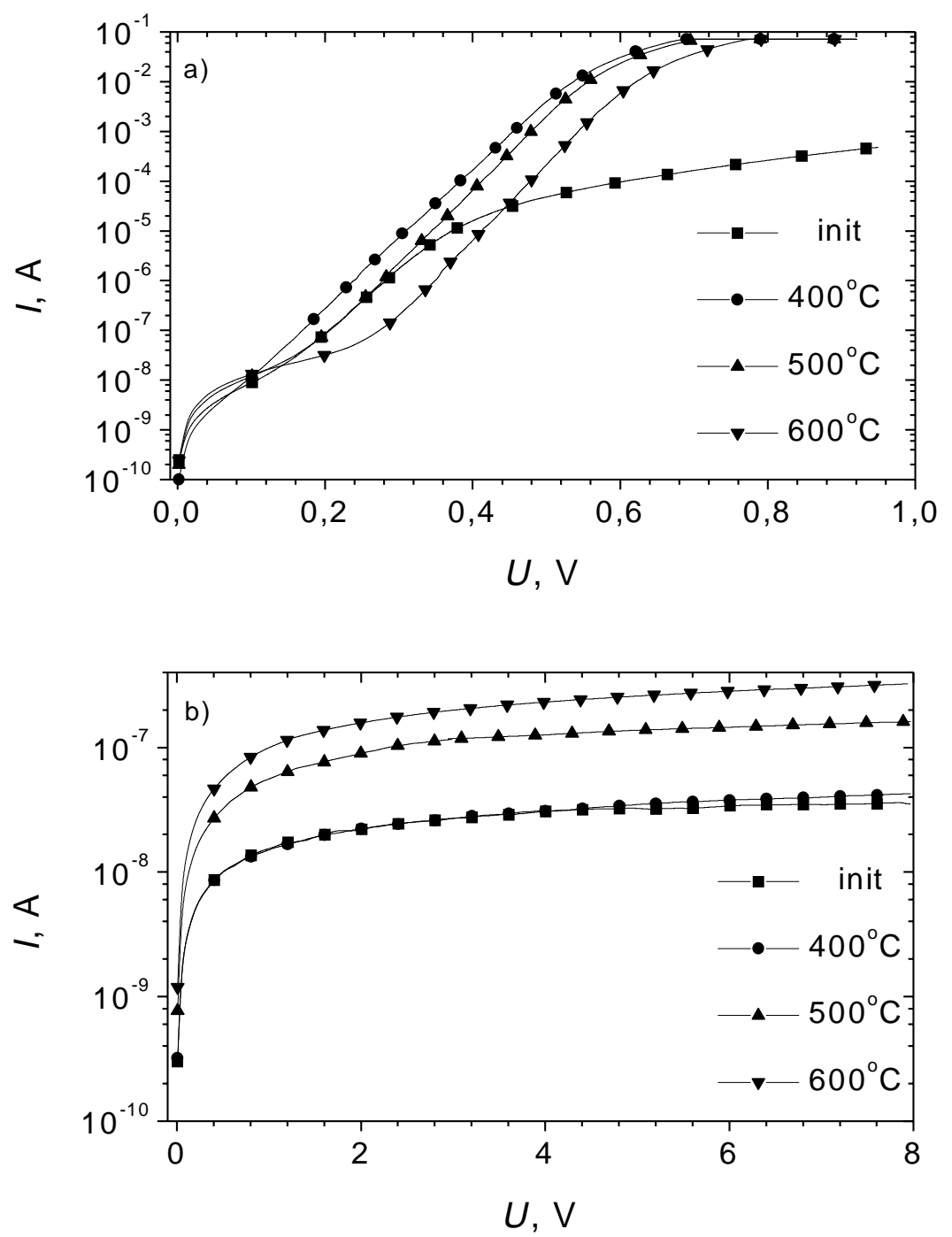

Fig. 8. Forward (a) and reverse (b) branches of the $I-V$ curves for the $\mathrm{Au}-\mathrm{TiB}_{x}-\mathrm{GaAs}$ contacts taken before and after heat annealing. 


\section{Ye. F. Venger et al.: Heat tolerance of titanium boride and titanium ...}

the centers with deep levels appear in the semiconductor near-surface region. Their nature is determined by reactions between phases, stresses, and semiconductor surface contamination with uncontrollable impurities from the surrounding parts. The above centers play some role in the current flow through the interface [8]. Taking into account some features of films appearance and growth during the magnetron sputtering, one may expect that impurities (e.g., copper observed by us) and defects will be distributed nonuniformly over the GaAs near-contact layers. Thus, there exists a quite actual possibility for some local regions of elevated defect concentration to appear in the space charge region. As a result, the differential slope $\left(1 / n=d \ln I_{F} / d V\right)$ of the forward branches of $I-V$ curves changes, as compared to that for an ideal contact. This means that an extra current flow component has appeared, and therefore the effective Schottky barrier height has dropped. Heat annealing at moderate $\left(\sim 400{ }^{\circ} \mathrm{C}\right)$ temperatures promotes partial reducing the concentration of the introduced defects, and among them, the compensating acceptors in the diode base. By this the structural uniformity of the GaAs nearcontact layers is improved (as confirmed also by the PL data) and the $I-V$ curves become similar to the "ideal" ones. This was observed in experiment ( see Fig. 8).

As annealing temperature grows, some additional defects appear (or the existing ones are modified) whose ionization energy is different from that of the initial defects. (In our case the concentration of $\left(\mathrm{Cu}_{\mathrm{Ga}}+\mathrm{V}_{\mathrm{As}}\right)$ complexes increased.) This results in appearance and further growth of a section at the forward branch of the $I-V$ curve that corresponds to excess currents. However, the thermionic mechanism of current flow still remains predominant. After annealing at a temperature of $800{ }^{\circ} \mathrm{C}$ the device parameters show considerable degradation. In this case, according to the Auger spectroscopy results, the antidiffusion properties of the barrier-forming layer decrease abruptly. As a result, the phases interact more intensively. This leads to modification of the structuralphase condition of the interface, as well as to dissociation of $\left(\mathrm{V}_{\mathrm{Ga}}+\mathrm{D}\right)$ and $\left(\mathrm{Cu}_{\mathrm{Ga}}+\mathrm{D}\right)$ complex centers. Some other defects (among them the centers responsible for fast nonradiative recombination) may, probably, be produced in large quantities in the GaAs near-contact region. Our results show that copper (entering the GaAs-based heterostructures as an uncontrollable impurity) apparently plays an important role in the degradation processes.

Thus, the present investigation has proved that the antidiffusion barrier-forming compositions on the base of titanium borides (nitrides) are promising for production of the surface-barrier structures with elevated thermal stability. To prevent contamination of the fabricated heterostructures with copper, some specific methods are to be used.

This work was partially supported by the Science and Technology Center of Ukraine (Project № 464).

\section{References}

1. T. N. Morgan, M. Pilkuhn, and H. Rupprecht // Phys. Rev. 138, p. 1551 (1965).

2. N. S. Averkiev, T. K. Ashirov, and A. A. Gutkin // Fiz. Tekhn. Poluprov., 15, p. 1970 (1981).

3. E. W. Williams // Phys. Rev. 168, p. 922 (1968).

4. C. E. McCants, T. Kendelewicz, P. H. Mahovald, K. A. Bertness, M. D. Williams, N. Newman, S. Lindau, and W.E. Spicer // J. Vac. Sci. Technol., A6(3), p. 1466 (1988).

5. J. Broser, H. Majer, and H.-J. Schulz // Phys. Rev., 140, p. 2135 (1965).

6. L. Bemberg and W. Schaires // Phys. Rev. Letters, 28, p. 442 (1972).

7. V. I. Strikha and E. V. Buzaneva, Physical Foundations of Reliability for the Metal - Semiconductor Contacts in Integrated Electronics (in Russian), Radio i Svyaz, Moscow (1987).

8. V. A. Labunov, I. L. Baranov, V. P. Bondarenko, and A. M. Dorofeev, Present-day methods of gettering in the semiconductor electronics technology (in Russian) // Zarubezhn. Elektron. Tekhnika, № 11, pp. 3-66 (1983). 